\title{
Regional cerebral saturation monitoring with near-infrared spectroscopy during selective antegrade cerebral perfusion: Diagnostic performance and relationship to postoperative stroke
}

\author{
Christian Olsson, MD, and Stefan Thelin, MD, PhD
}

Supplemental material is available online.
From Uppsala University Hospital, Department of Surgical Sciences, Division of Cardiothoracic Surgery, Uppsala, Sweden.

Read at the Eighty-fifth Annual Meeting of The American Association for Thoracic Surgery, San Francisco, Calif, April 10-13, 2005.

Received for publication April 6, 2005; revisions received Aug 15, 2005; accepted for publication Aug 31, 2005.

Address for reprints: Christian Olsson, MD, Thoraxkliniken, Akademiska sjukhuset, SE751 85, Uppsala, Sweden (E-mail: christian. olsson@surgsci.uu.se).

J Thorac Cardiovasc Surg 2006;131:371-9

$0022-5223 / \$ 32.00$

Copyright $\odot 2006$ by The American Association for Thoracic Surgery

doi:10.1016/j.jtcvs.2005.08.068
Objective: To investigate whether regional cerebral tissue oxygen saturation monitoring during hypothermic selective antegrade cerebral perfusion in surgery involving the aortic arch can predict neurologic sequelae and to evaluate the diagnostic performance of near-infrared spectroscopy monitoring in this setting.

Methods: Data from 46 consecutive patients were analyzed. Selective antegrade cerebral perfusion was established by perfusion of the right subclavian artery (with or without left carotid artery perfusion) or by separate concomitant perfusion of the innominate and the left carotid arteries. The bilateral regional cerebral tissue oxygen saturation index was monitored by using near-infrared spectroscopy equipment (INVOS 4100). Stroke was the primary clinical end point, along with the indices of diagnostic performance.

Results: Six patients died in the hospital, and 6 patients (13\%) experienced a perioperative stroke. In patients with stroke, regional cerebral tissue oxygen saturation values were significantly lower during selective antegrade cerebral perfusion, and regional cerebral tissue oxygen saturation tended to be lower in the affected hemisphere. In receiver operating characteristic curve analysis, the area under the curve for relative regional cerebral tissue oxygen saturation values ranged from 0.72 to 0.87 . During selective antegrade cerebral perfusion, regional cerebral tissue oxygen saturation between $76 \%$ and $86 \%$ of baseline had a sensitivity up to $83 \%$ and a specificity up to $94 \%$ in identifying individuals with stroke. The associated odds ratio for stroke was 5.6 (95\% confidence interval, $0.5-144)$ to 21 (95\% confidence interval, 1.8-566).

Conclusions: Monitoring of regional cerebral tissue oxygen saturation by using near-infrared spectroscopy during selective antegrade cerebral perfusion allows detection of clinically important cerebral desaturation. It can help predict perioperative neurologic sequelae. Its performance as a diagnostic instrument is satisfying and supports its use as a noninvasive trend monitor of cerebral saturation.

I $\mathrm{n}$ operations extending to the transverse aortic arch, selective antegrade cerebral perfusion (SACP) has been introduced and developed to decrease the potential for cerebral damage associated with the hypothermic circulatory arrest (HCA) strategy. ${ }^{1}$ Aiming at increased safety and improved neurologic outcome, monitoring of cerebral tissue oxygenation during SACP by near-infrared spectroscopy (NIRS), among other techniques, has been used clinically. ${ }^{2-5}$ The NIRS equipment provides monitoring of regional cerebral tissue oxygen saturation $\left(\mathrm{rSO}_{2}\right)$ in a continuous, noninvasive, and examiner-independent fashion. The results of clinical and experimental use of NIRS monitoring have been promising, ${ }^{3,4,6-8}$ but opinions about its dependency and usefulness have been equivocal. ${ }^{9-11}$ The diagnostic performance 


\author{
Abbreviations and Acronyms \\ AUC $=$ area under the curve \\ $\mathrm{CPB}=$ cardiopulmonary bypass \\ HCA = hypothermic circulatory arrest \\ NIRS $=$ near-infrared spectroscopy \\ $\mathrm{ROC}=$ receiver operating characteristic \\ $\mathrm{rSO}_{2}=$ regional cerebral tissue oxygen saturation \\ $\mathrm{SACP}=$ selective antegrade cerebral perfusion
}

expressed in terms that could serve as an evidence base for the method has not been reported in this patient group.

In this study, bilateral intraoperative NIRS monitoring was used in patients undergoing operations involving the aortic arch with the aid of SACP. The objective was to examine the overall diagnostic performance of the NIRS monitoring method in this clinical setting. The primary goals were to evaluate the ability to predict perioperative stroke and to test the hypothesis that a lower $\mathrm{rSO}_{2}$ is associated with an increased stroke risk. Secondary goals were to investigate the correlation between $\mathrm{rSO}_{2}$ and standard monitoring (arterial blood gas components, mean arterial pressure, and hematocrit) and to investigate the influence of the SACP strategy (bilateral or unilateral cerebral perfusion) on $\mathrm{rSO}_{2}$ values.

\section{Patients and Methods \\ Patients and Definitions}

The 46 patients were operated on consecutively between January 2003 and September 2004, and data were analyzed retrospectively. Inclusion criteria were operations involving the aortic arch and cerebral protection with SACP. No patient who met these criteria was excluded from analysis. Computed tomography of the aorta was the mainstay of diagnosis, and this was supplemented by echocardiography as clinically indicated. Duplex scan of the carotid arteries was not performed routinely. Mortality was defined as allcause in-hospital mortality. Stroke was defined as any new neurologic deficit that did not resolve before discharge and that was confirmed with computed tomography, specialist neurologic assessment, or both.

\section{Surgery and SACP}

Three different setups for SACP were used: (1) right-sided unilateral SACP through a subclavian artery cannula, (2) bilateral SACP through the combination of a right-sided subclavian artery cannula and a separate left carotid artery cannula, and (3) bilateral SACP through 2 separate cannulas (DLP 15F coronary sinus cannula; Medtronic Inc, Minneapolis, Minn) in the innominate and left carotid arteries. The choice of SACP strategy was nonrandomized and surgeon driven. The subclavian artery was cannulated with a wirereinforced $18 \mathrm{~F}$ to $22 \mathrm{~F}$ femoral arterial cannula (FemFlex II
[Medtronic Inc] or EOPA [Edwards Lifesciences, Irvine, Calif]). The left subclavian artery was not perfused. In most cases it was left unclamped to verify back-bleeding and aid in the deairing of the arch on completion of the distal anastomosis. Venous return was obtained from a 2-stage right atrial cannula or from a long 2-stage femoral vein cannula. The proximal aorta was addressed during cooling to $18^{\circ} \mathrm{C}$ to $25^{\circ} \mathrm{C}$ nasopharyngeal temperature. At the target temperature, with the head packed in ice, the circulation was arrested and the venous blood drained into the reservoir. After inspection of the arch, the proximal innominate artery was snared, and SACP was started at 250 to $500 \mathrm{~mL} / \mathrm{min}$. A second cannula was added in the left carotid, and flow was increased to 500 to $1000 \mathrm{~mL} / \mathrm{min}$ (approximately $10 \mathrm{~mL} \cdot \mathrm{kg}^{-1} \cdot \mathrm{min}^{-1}$, according to previously reported findings ${ }^{12,13}$ ). In cases without subclavian artery cannulation, right radial artery pressure was maintained at 40 to $70 \mathrm{~mm} \mathrm{Hg}$ to avoid hypoperfusion and hyperperfusion ${ }^{12,13}$; otherwise, calculated flow was maintained and not corrected for nasopharyngeal temperature. Acid-base balance was managed with the alpha-stat strategy, and hematocrit was adjusted to reach $25 \%$ to $28 \%$ at the conclusion of cardiopulmonary bypass (CPB), with blood transfusions as required. At completion of the open distal anastomosis, the cannulas were removed, the arch was carefully deaired, and CPB was recommenced, either through the right subclavian artery cannula or by cannulating the anastomosed tube graft.

\section{Near-Infrared Spectroscopy}

The principles of NIRS have been described in detail previously. ${ }^{11,14,15}$ In brief, light in the 650 - to $1100-\mathrm{nm}$ interval (i.e., including near-infrared light) is to the largest extent absorbed in tissues by the oxygenated and deoxygenated forms of hemoglobin. Hence, according to the modified Lambert-Beer law, light absorbance is proportional to the concentrations of these chromophores. ${ }^{14}$ From these concentrations, tissue saturation can be derived. The INVOS 4100 cerebral oximeter (Somanetics Corp, Troy, Mich) was used for bilateral monitoring of $\mathrm{rSO}_{2}$ throughout the operations. Readings were obtained continuously and recorded at prespecified time points. Two single-use adhesive patches (Adult Soma Sensor SAFB; Somanetics Corp) were placed on the forehead: the frontal sinuses, the sagittal sinus, and the temporal muscles were avoided. Near-infrared light was emitted from a light-emitting diode source and detected at 2 separate distances ( 3 and $4 \mathrm{~cm}$ ) to allow subtraction of the contribution to the signal by superficial tissues. According to the manufacturer, on average $85 \%$ of the signal is of cerebral origin. Two wavelengths (730 and $810 \mathrm{~nm}$ ) are used to detect changes in hemoglobin oxygenation. In the INVOS algorithm, calculation of $\mathrm{rSO}_{2}$ depends on the relative contributions of venous and arterial compartments, considered stable at a 75:25 ratio. The $\mathrm{rSO}_{2}$ readings 
TABLE 1. Preoperative variables of all patients, patients without stroke, and patients with stroke

\begin{tabular}{|c|c|c|c|c|}
\hline & \multirow{2}{*}{$\begin{array}{c}\text { All } \\
(n=46)\end{array}$} & \multicolumn{2}{|c|}{ Stroke } & \multirow{2}{*}{$\begin{array}{c}P \\
\text { value }\end{array}$} \\
\hline & & No $(n=40)$ & Yes $(n=6)$ & \\
\hline Men & $31(67 \%)$ & $28(70 \%)$ & $3(50 \%)$ & .30 \\
\hline Age, y & $61(53-67)$ & $59(53-66)$ & 66 (63-73) & .09 \\
\hline Age $>70$ y & $9(20 \%)$ & $7(18 \%)$ & $2(33 \%)$ & .33 \\
\hline \multicolumn{5}{|l|}{ Diagnosis } \\
\hline Acute A & $25(54 \%)$ & $20(50 \%)$ & $5(83 \%)$ & .14 \\
\hline Chron A & $5(11 \%)$ & $4(10 \%)$ & $1(17 \%)$ & .52 \\
\hline Asc Ane & $14(30 \%)$ & $14(35 \%)$ & 0 & 10 \\
\hline Other* & $2(4 \%)$ & $2(5 \%)$ & 0 & .75 \\
\hline Acute & $23(50 \%)$ & $19(48 \%)$ & $4(67 \%)$ & .33 \\
\hline Rupture & $15(33 \%)$ & $15(38 \%)$ & 0 & .15 \\
\hline EuroSCORE & $9(7-10)$ & $8.5(7-10.5)$ & $9.5(9-10)$ & .43 \\
\hline EuroSCORE $>8$ & $17(37 \%)$ & $24(60 \%)$ & $5(83 \%)$ & .39 \\
\hline Stroke Hx & 0 & 0 & 0 & $n / a$ \\
\hline
\end{tabular}

Numbers with percentages and medians with 25th and 75th centiles. Acute $A$, Acute type A aortic dissection; Chron A, chronic type A aortic dissection; Asc Ane, ascending aortic aneurysm; $H x$, history. *One aneurysm of the arterial duct; one thoracoabdominal tumor.

are expressed as an index, measuring differences from an unknown baseline. No other method of cerebral monitoring was used.

\section{Statistical Methods}

No assumptions of normal distributions of the variables were made, and nonparametric statistical tests were used: Mann-Whitney $U$ test (continuous variables) and Fisher exact test (dichotomous variables). Changes in $\mathrm{rSO}_{2}$ were expressed in relative terms as the percentage of baseline set at $100 \%$ when stable conditions were reached on full-flow

TABLE 2. Perfusion-related variables for all patients, patients without stroke, and patients with stroke

\begin{tabular}{lcccc}
\hline & \multicolumn{4}{c}{ Stroke } \\
\cline { 2 - 5 } & All (n= 46) & No (n = 40) & Yes (n=6) & $P$ value \\
\hline CPB time, min & $220(192-286)$ & $220(188-289)$ & $220(210-230)$ & .76 \\
HCA time, min & $38(28-51)$ & $38(28-52)$ & $37(33-47)$ & .84 \\
SACP time, & $32(25-46)$ & $33(26-50)$ & $25(19-32)$ & .06 \\
$\quad$ min & & & & \\
Unperfused & $29(63 \%)$ & $23(58 \%)$ & $6(100 \%)$ & .07 \\
$\begin{array}{l}\text { Unperfused } \\
\text { time, min }\end{array}$ & $2(0-11)$ & $2(0-10)$ & $16(7-18)$ & .004 \\
$\begin{array}{c}\text { Bilateral } \\
\text { SACP }\end{array}$ & $40(87 \%)$ & $37(92 \%)$ & $3(50 \%)$ & .004 \\
Lowest body & $20(19-22)$ & $20(19-22)$ & $20(19-21)$ & .64 \\
temp, ${ }^{\circ} \mathrm{C}$ & & & & \\
\hline
\end{tabular}

Numbers with percentages and medians with 25th and 75th centiles. CPB, Cardiopulmonary bypass; HCA, hypothermic circulatory arrest; SACP, selective antegrade cerebral perfusion.

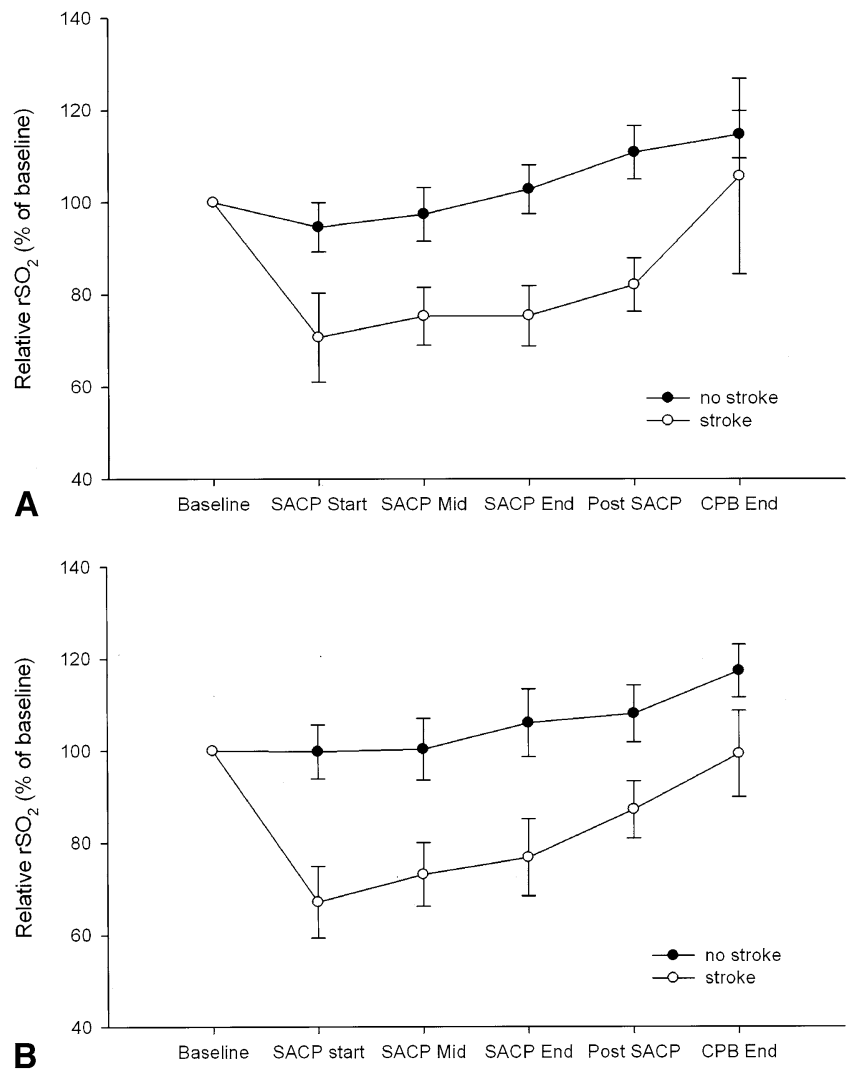

Figure 1. The $\mathrm{rSO}_{2}$ relative to baseline $(100 \%)$ in the $(\mathrm{A})$ left and $(\mathrm{B})$ right hemispheres in patients without $(n=40)$ and with $(n=6)$ stroke. Data are mean and SEM.

normothermic CPB. Calculation of the area under the curve (AUC) of the receiver operating characteristic (ROC), with 95\% confidence intervals, was used to evaluate diagnostic accuracy ${ }^{16,17}$ by using a semiparametric method (Analyse-it Software Ltd, Leeds, United Kingdom). Cutoff values for the highest sensitivity and specificity were identified at each time point in both hemispheres. On the basis of the cutoff value, diagnostic performance indices (sensitivity, specificity, positive predictive value, negative predictive value, and positive and negative likelihood ratios) were calculated (Appendix E1).

\section{Results}

The clinical characteristics of the patients are summarized in Table 1. Six patients (13\%) died in the hospital. The cause of death was bleeding in 3 , cardiac failure in 2 , and stroke in 1 . None of the 5 patients dead of nonneurologic complications showed signs of cerebral injury at autopsy. Six patients (13\%) had a perioperative stroke. In 1, it was global (leading to death), in 3 it was left hemispheric, and in 2 it was right hemispheric. Excluding the patients with 

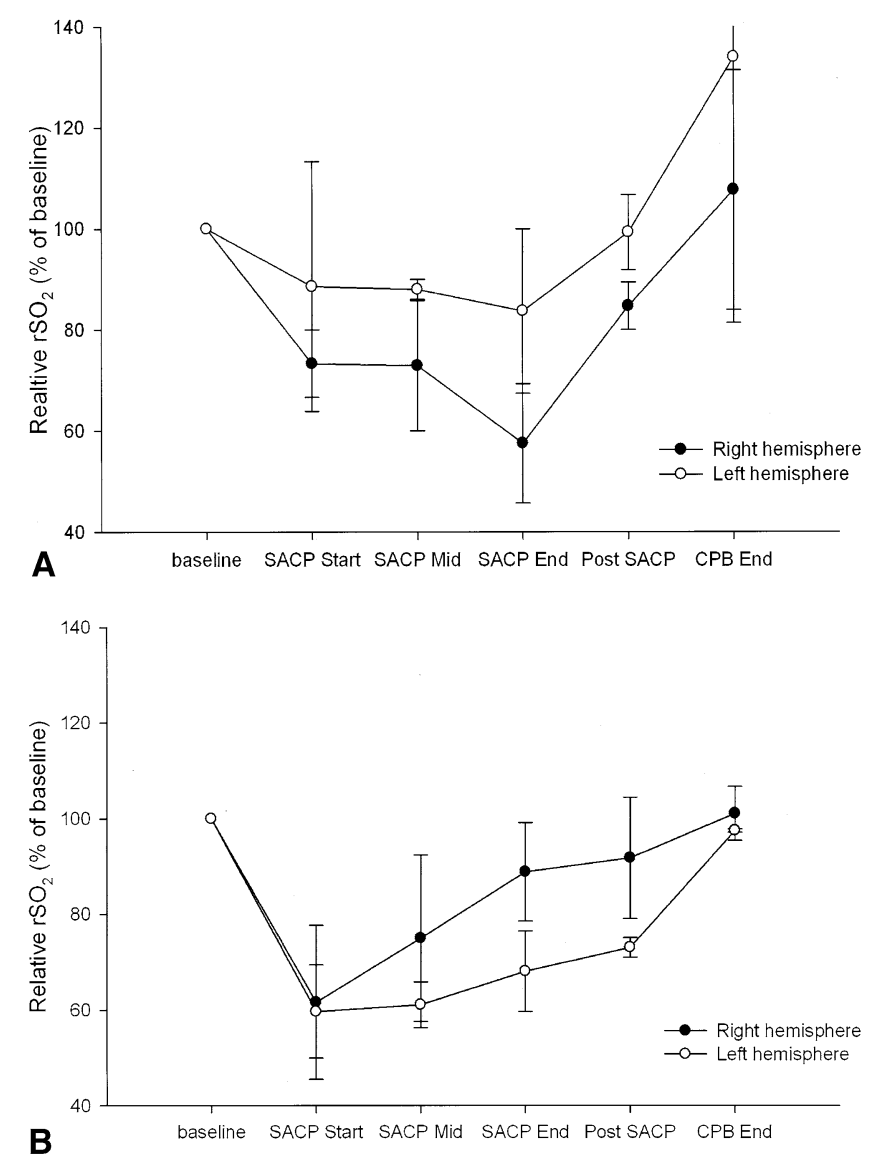

Figure 2. The $\mathrm{rSO}_{2}$ relative to baseline $(100 \%)$ in both hemispheres in $(A)$ left $(n=3)$ and $(B)$ right $(n=2)$ hemispheric strokes. Data are mean and SEM.

stroke, 2 (4.3\%) had temporary nonfocal neurologic symptoms: seizures and impaired consciousness that resolved gradually. One patient had bilateral optic nerve infarctions after a free interval after surgery and was not included among the stroke cases. The prevalence of periods of HCA without ongoing SACP (termed unperfused brain), the median duration of such periods, and the use of unilateral SACP were associated with perioperative stroke (Table 2).

Direct readings of the $\mathrm{rSO}_{2}$ index varied widely between subjects and were not useful for group comparisons. When expressed as percentage of baseline, a significant difference was found in patients free from stroke compared with those with stroke: in the latter, relative $\mathrm{rSO}_{2}$ was bilaterally significantly reduced during SACP, to levels $65 \%$ to $80 \%$ of baseline (Figure 1). In patients without stroke, only the left hemispheric $\mathrm{rSO}_{2}$ at the beginning of SACP was significantly decreased compared with baseline, whereas in stroke, $\mathrm{rSO}_{2}$ in both hemispheres at all time points except for after SACP in the right hemisphere was significantly lower than baseline. In patients with left hemispheric strokes, relative
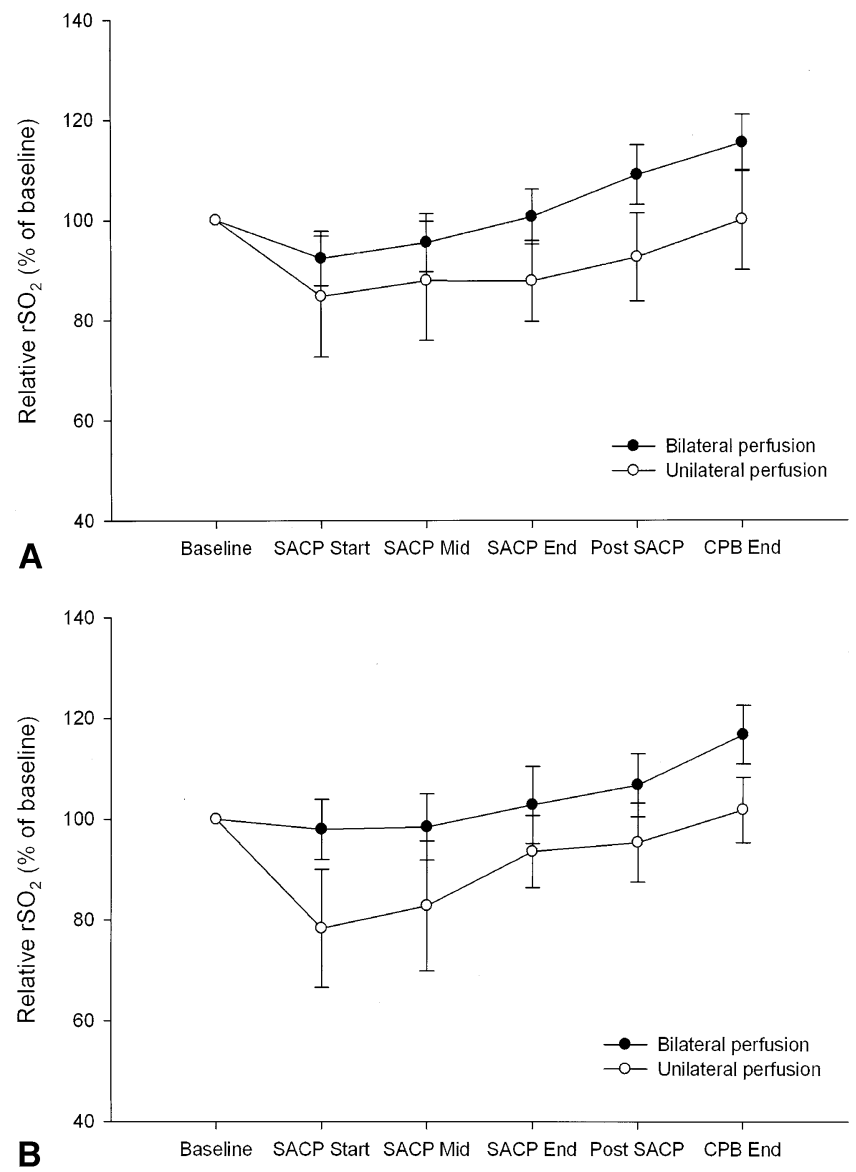

Figure 3. The $\mathrm{rSO}_{2}$ relative to baseline $(100 \%)$ in the (A) left and (B) right hemispheres with bilateral $(n=37)$ and unilateral $(n=9)$ selective antegrade cerebral perfusion (SACP). Data are mean and SEM.

$\mathrm{rSO}_{2}$ values were lower on the left side than on the right, with a corresponding similar but less pronounced pattern for right hemispheric strokes (Figure 2). Bilateral cerebral perfusion $(\mathrm{n}=40)$ resulted in higher $\mathrm{rSO}_{2}$ values in both hemispheres throughout the operation compared with patients managed with unilateral SACP $(n=6)$, with significantly higher right hemispheric readings at the onset of SACP and at the conclusion of CPB (Figure 3).

ROC curves for $\mathrm{rSO}_{2}$ values of both hemispheres at consecutive time points during SACP are illustrated in Figure 4. The $\mathrm{rSO}_{2}$ at the onset of SACP displayed the best diagnostic accuracy. Apart from values obtained at the end of CPB, ROC curve AUCs were similar throughout operation and were significantly different from 0.5 , as illustrated in Table 3. Sensitivity reached a high $83 \%$ at the onset of SACP, whereas specificity was highest, $94 \%$, in right hemispheric readings after SACP, albeit at a lower cutoff value (77\% of baseline). Overall, negative predictive values 

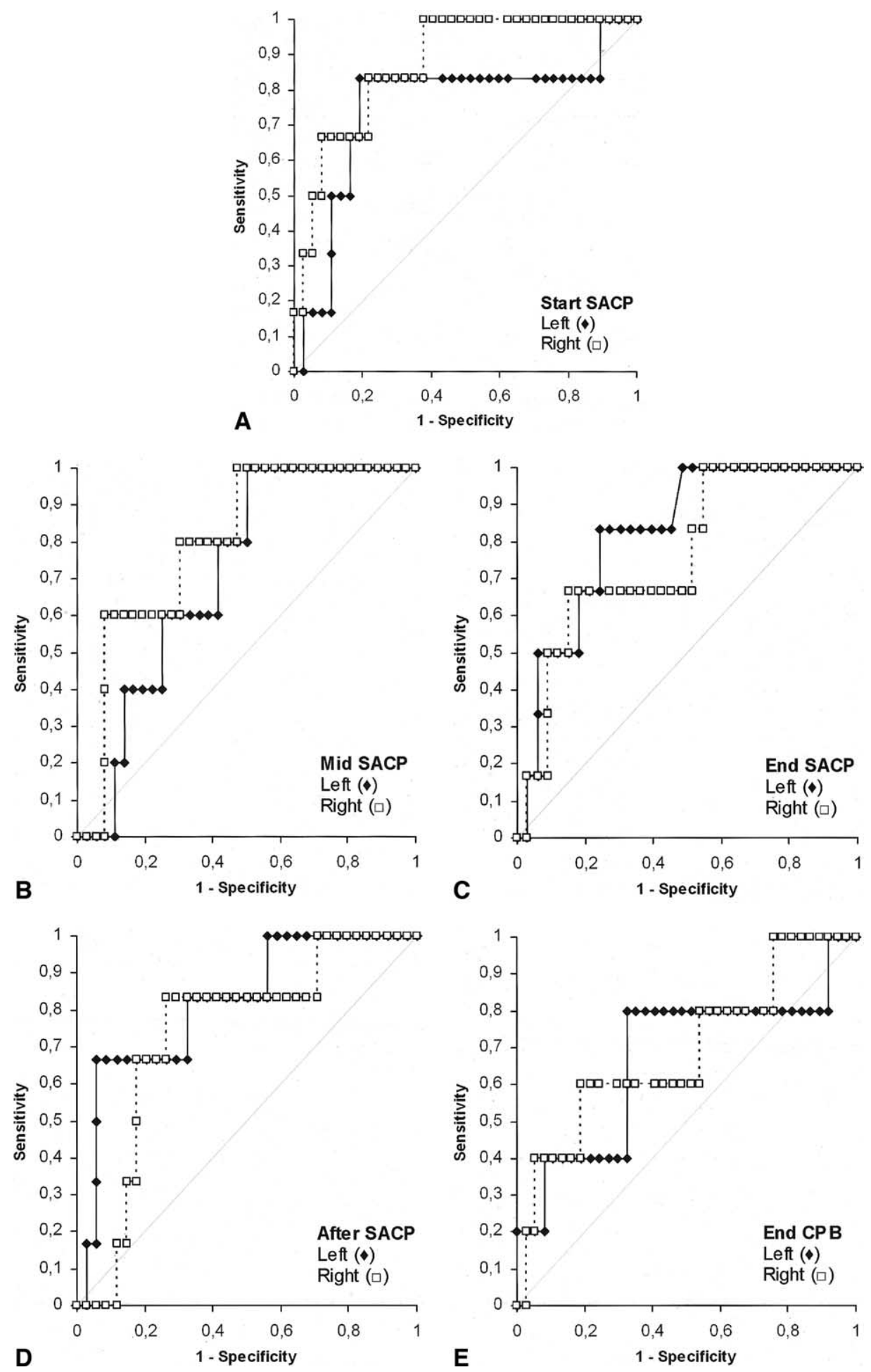

Figure 4. Receiver operating characteristic (ROC) curves for $\mathrm{rSO}_{2}$ relative to baseline $(100 \%)$ at the start of selective antegrade cerebral perfusion (SACP) (A), mid SACP (B), end of SACP (C), after SACP (D), and end of cardiopulmonary bypass (CPB) (E). 
TABLE 3. Diagnostic performance indices of right and left hemispheric relative regional cerebral tissue oxygen saturation values during and after the period of selective antegrade cerebral perfusion (SACP)

\begin{tabular}{lccccc}
\hline \multirow{2}{*}{ Variable } & \multicolumn{2}{c}{ SACP start } & & \multicolumn{2}{c}{ SACP mid } \\
\cline { 2 - 3 } \cline { 5 - 5 } & Right & Left & & Right & Left \\
\hline ROC area & $0.87(0.75-1.0)$ & $0.75(0.52-1.0)$ & & $0.79(0.62-0.97)$ & $0.72(0.54-0.90)$ \\
Cutoff value (\% of baseline) & 81 & 76 & & 87 & 86 \\
Sensitivity & $0.83(0.39-0.99)$ & $0.83(0.39-0.99)$ & & $0.80(0.18-0.92)$ & $0.80(0.32-0.99)$ \\
Specificity & $0.78(0.71-0.81)$ & $0.81(0.74-0.84)$ & & $0.89(0.83-0.93)$ & $0.58(0.52-0.61)$ \\
Positive predictive value & $0.39(0.18-0.46)$ & $0.42(0.20-0.50)$ & & $0.43(0.13-0.66)$ & $0.21(0.08-0.26)$ \\
Negative predictive value & $0.97(0.88-1.0)$ & $0.97(0.88-1.0)$ & & $0.94(0.88-0.99)$ & $0.96(0.84-1.0)$ \\
Likelihood ratio (positive) & 3.9 & 4.4 & & 5.2 & 1.9 \\
Likelihood ratio (negative) & 0.2 & 0.2 & & 0.4 & 0.3 \\
Odds ratio & $18(1.6-470)$ & $21(1.8-566)$ & & $12(1.1-157)$ & $5.6(0.5-144)$ \\
Relative risk & $12(1.5-255)$ & $13(1.7-286)$ & & $7.1(1.1-54)$ & $4.6(0.5-107)$ \\
\hline
\end{tabular}

were better than positive predictive values, and positive likelihood ratios were better than negative likelihood ratios (Table 3).

In a handful of cases, $\mathrm{rSO}_{2}$ decreased suddenly because of technical errors such as cannula dislodgment or arterial line compromise, and this necessitated prompt countermeasures. Such episodes were temporary, and we did not identify any relationship to the $\mathrm{rSO}_{2}$ levels during the remainder of the perfusion or to clinical outcome.

Intraoperative measurements of blood gas components $(\mathrm{pH}$, arterial partial pressure of oxygen and carbon dioxide, base excess, arterial saturation, and hematocrit) and mean arterial pressure showed no relation to neurologic outcome. These variables correlated with values of $\mathrm{rSO}_{2}$ in either hemisphere only vaguely and without a distinct pattern (Table E1).

\section{Discussion}

Patients with perioperative stroke did not differ from strokefree individuals in preoperative characteristics. However, patients with perioperative stroke more often had episodes of unperfused brain (100\% vs $58 \%$ ), and the aggregated time of unperfused brain was significantly longer in stroke victims (16 vs 2 minutes, respectively). Stroke was more common after a strategy of unilateral rather than bilateral SACP (50\% vs $7.5 \%$; Table 2). These findings suggest a higher risk of perioperative stroke in cases in which brain protection, despite the use of SACP, was suboptimal, and they reflect the vulnerability of patients undergoing aortic arch operations.

With stroke, $\mathrm{rSO}_{2}$ was significantly lower bilaterally and without interruption until after the completion of CPB (Figure 2). Furthermore, $\mathrm{rSO}_{2}$ showed a pattern of lower levels in the affected hemisphere than in the nonaffected hemisphere (Figure 3), thus supporting the hypothesis of a relationship between lower intraoperative $\mathrm{rSO}_{2}$ and periopera- tive stroke. A similar pattern was found when bilateral and unilateral SACP were compared (Figure 4, $A$ and $B$ ), with consistently lower values in both hemispheres during unilateral SACP. This contributes to the explanation of the finding of fewer strokes with bilateral SACP. In experimental studies, longer periods of $\mathrm{HCA}$ equaling lower $\mathrm{rSO}_{2}$ and prolonged periods to recovery of baseline $\mathrm{rSO}_{2}$ have been associated with cerebral complications. ${ }^{6,8}$ Minimizing periods of HCA without SACP could be important to prevent cerebral damage, especially when operations are performed at moderate rather than deep hypothermia.

In assessing the diagnostic performance of the NIRS method of monitoring $\mathrm{rSO}_{2}$, several diagnostic indices were calculated on the basis of the recorded readings (Table 3). In the ROC curve analysis, true-positive cases are plotted against true-negative cases, and the resulting function delineates an area, the AUC, that represents the overall performance of the test. The AUC is a close approximation of the probability that the test is correct for any given value. Generally, the ROC curve AUC should be at least 0.75 to be clinically valuable. ${ }^{17}$ This was the case for all but 1 leftsided time point (mid SACP) and 1 right-sided time point (after SACP). Right-sided readings at the beginning of SACP and left-sided readings at the end of SACP were singled out as the individual time points with the largest AUC. Cutoff values for each individual time point were determined and served as the basis for the corresponding diagnostic indices. Cutoffs varied between 76 at the start of SACP and 86 after SACP, with an overall mean of 83, expressed as a percentage of baseline (100). Below these cutoffs, the odds ratio for stroke increased to 32, and relative risk increased to 13 (Table 3). Overall, sensitivity was higher than specificity (Table 3). Furthermore, negative predictive values and positive likelihood ratios were higher than positive predictive values and negative likelihood ratios. These are key findings indicating that episodes of 


\begin{tabular}{ccccc} 
& SACP end & & \multicolumn{2}{c}{ After SACP } \\
\cline { 5 - 5 } Right & Left & Right & Left \\
$0.76(0.57-0.96)$ & $0.83(0.67-0.98)$ & 84 & $0.74(0.54-0.93)$ & 91 \\
81 & $0.83(0.39-0.99)$ & $0.83(0.39-0.99)$ & $0.82(0.64-1.0)$ \\
$0.67(0.26-0.94)$ & $0.76(0.68-0.79)$ & $0.74(0.66-0.76)$ & 77 \\
$0.85(0.78-0.90)$ & $0.39(0.18-0.46)$ & $0.36(0.17-0.43)$ & $0.67(0.27-0.91)$ \\
$0.44(0.18-0.62)$ & $0.96(0.86-1.0)$ & $0.96(0.86-1.0)$ & $0.94(0.87-0.99)$ \\
$0.93(0.85-0.99)$ & 3.4 & 3.1 & $0.67(0.27-0.91)$ \\
4.4 & 0.2 & 0.2 & $0.94(0.87-0.99)$ \\
0.4 & $16(1.4-407)$ & $14(1.2-457)$ & 11.3 \\
$11(1.2-127)$ & $10(1.3-221)$ & $9.3(1.2-206)$ & 0.3 \\
$6.7(1.2-49)$ & & & $32(2.5-667)$ \\
& & & & $11(2.1-59)$ \\
\hline
\end{tabular}

harmful desaturation rarely go undetected, at the expense of a proportion of false-positive cases. We find it better to err on the side of sensitivity and adjust cannulas, flow, temperature, and the surgical approach to try to correct a low $\mathrm{rSO}_{2}$. The NIRS monitor also rapidly identified perfusion-related problems that otherwise could be very harmful yet go undetected.

Our findings corroborate those of Samra and associates, ${ }^{18}$ who studied 99 patients undergoing carotid endarterectomy with bilateral NIRS monitoring. They reported a larger decrease of ipsilateral $\mathrm{rSO}_{2}(12.2 \%$ vs $4.8 \%)$ during crossclamping of the carotid artery in patients with postoperative neurologic symptoms, and they identified a cutoff point of a $20 \%$ decrease from baseline: this yielded an $80 \%$ sensitivity and $82.2 \%$ specificity but a $66.7 \%$ false-positive rate. Orihashi and colleagues ${ }^{4}$ studied $\mathrm{rSO}_{2}$ in 59 patients undergoing aortic arch operations with SACP. In 16 patients (27\%) with cerebral complications, they found sustained periods of $\mathrm{rSO}_{2}$ less than $55 \%$ or $60 \%$, which were cutoffs chosen from accepted lowest values of jugular vein bulb venous saturation and estimated "normal" cerebral tissue saturation. It is interesting to note that their findings applied only to patients who sustained cerebral damage attributable to hypoperfusion; according to the authors, embolic strokes went undetected by $\mathrm{rSO}_{2}$. In other studies, it has been shown that $\mathrm{rSO}_{2}$ remains at baseline in patients without cerebral complications ${ }^{5}$ and that a decline in $\mathrm{rSO}_{2}$ of approximately $40 \%$ is associated with impaired neuropsychological performance. ${ }^{19}$ Kirkpatrick and colleagues ${ }^{20}$ demonstrated in neurosurgical patients that a desaturation in the magnitude of $25 \%$ to $30 \%$ (from a baseline of $75 \%$ ) corresponded to an episode of severe cerebral ischemia. Evidently, studies in different patient populations are coherent in their findings of a critical $\mathrm{rSO}_{2}$ level in the interval of $25 \%$ to $40 \%$ below baseline, or approximately $50 \%$ in $\mathrm{rSO}_{2}$ index readings. Our results support these findings and add further support to their application by introducing data regarding the diagnostic performance of the NIRS method. In our opinion, the diagnostic performance of intraoperative NIRS monitoring, although not perfect, is good enough to recommend its clinical use both to guide the conduct of cerebral perfusion and to predict perioperative stroke.

Despite theoretical concerns about the NIRS methodspecifically, its ability to adequately monitor cerebral tissue rather than the overlying structures ${ }^{21}$-there are several reports that support its use, demonstrating good correlations between $\mathrm{rSO}_{2}$ and magnetic resonance findings, ${ }^{22}$ histologic findings, ${ }^{6,8,23}$ alterations in cerebral and systemic biochemical markers of tissue damage, ${ }^{8}$ and jugular vein bulb venous saturation, ${ }^{5,24}$ a method assumed to represent the overall oxygen consumption of the brain. To the best of our knowledge, none of the mentioned methods has been fully evaluated as a diagnostic test by using the indices of this report, which are considered essential for an evidence-based use of a diagnostic instrument.

Arterial blood gases, mean arterial pressures, and hematocrit correlated only weakly and insignificantly with $\mathrm{rSO}_{2}$ irrespective of the phase of the operation (Table E1). These findings in part differ from those of Nollert and associates, ${ }^{25}$ who report correlations of $\mathrm{rSO}_{2}$ with $\mathrm{pCO}_{2}$ and also of oxidized cytochrome to $\mathrm{pH}$, temperature, and hemoglobin. However, most of their patients underwent coronary surgery and other operations with standard CPB. Patients underwent operation under moderate hypothermia $\left(26^{\circ} \mathrm{C}\right)$. Aortic surgery and SACP were not represented, and NIRS monitoring was unilateral (left hemisphere). It is interesting to note that $\mathrm{rSO}_{2}$ showed a correlation with measured variables only during $\mathrm{CPB}$. No patient experienced stroke after surgery, and the ability of $\mathrm{rSO}_{2}$ to predict stroke could not be evaluated. In our opinion, standard intraoperative monitoring does not adequately represent cerebral tissue saturation; it does not predict neu- 
rologic outcome and cannot safely replace a method of monitoring the brain directly.

There are several limitations of this study. It includes a small number of patients. Some of the data were collected retrospectively. Patients were not randomized to the different SACP strategies, and there is no control group for comparison of NIRS data. Some important variables, eg, hematocrit, were not included in the analysis. The findings of this study need to be confirmed in larger, well-designed studies, preferably studies that use continuous intraoperative NIRS data.

In summary, the application of NIRS to measure $\mathrm{rSO}_{2}$ in cerebral tissue during SACP seems to provide important information that can be used to improve intraoperative perfusion performance and to predict perioperative neurologic outcome. The diagnostic properties of the method are good but not perfect. Information during the initiation of SACP, specifically at moderate hypothermia when the brain is not perfused, is the most important. Standard intraoperative monitoring correlates poorly with $\mathrm{rSO}_{2}$ and cannot replace its use. Knowledge of critical $\mathrm{rSO}_{2}$ levels and diagnostic performance is fundamental to the application of the method, and we anticipate a more widespread use that includes broader patient groups and further technical advancements of the monitoring devices.

\section{References}

1. Ergin MA, Galla JD, Lansman L, Quintana C, Bodian C, Griepp RB. Hypothermic circulatory arrest in operations on the thoracic aorta. Determinants of operative mortality and neurologic outcome. J Thorac Cardiovasc Surg. 1994;107:788-97; discussion 797-9.

2. Daubeney PE, Pilkington SN, Janke E, Charlton GA, Smith DC, Webber SA. Cerebral oxygenation measured by near-infrared spectroscopy: comparison with jugular bulb oximetry. Ann Thorac Surg. 1996;61:930-4.

3. Daubeney PE, Smith DC, Pilkington SN, Lamb RK, Monro JL, Tsang VT, et al. Cerebral oxygenation during paediatric cardiac surgery: identification of vulnerable periods using near infrared spectroscopy. Eur J Cardiothorac Surg. 1998;13:370-7.

4. Orihashi K, Sueda T, Okada K, Imai K. Near-infrared spectroscopy for monitoring cerebral ischemia during selective cerebral perfusion. Eur J Cardiothorac Surg. 2004;26:907-11.

5. Kawashima Y, Takamoto S. Brain protection in aortic surgery: proceedings of the International Symposium on Current Techniques for Brain Protection in Aortic Surgery, Osaka, Japan, 15-16 September 1996. Amsterdam: Elsevier; 1997.

6. Sakamoto T, Hatsuoka S, Stock UA, Duebener LF, Lidov HG, Holmes GL, et al. Prediction of safe duration of hypothermic circulatory arrest by near-infrared spectroscopy. J Thorac Cardiovasc Surg. 2001;122: 339-50.

7. Sakamoto T, Jonas RA, Stock UA, Hatsuoka S, Cope M, Springett RJ, et al. Utility and limitations of near-infrared spectroscopy during cardiopulmonary bypass in a piglet model. Pediatr Res. 2001;49:770-6.

8. Shin'oka T, Nollert G, Shum-Tim D, du Plessis A, Jonas RA. Utility of near-infrared spectroscopic measurements during deep hypothermic circulatory arrest. Ann Thorac Surg. 2000;69:578-83.

9. Lewis SB, Myburgh JA, Thornton EL, Reilly PL. Cerebral oxygenation monitoring by near-infrared spectroscopy is not clinically useful in patients with severe closed-head injury: a comparison with jugular venous bulb oximetry. Crit Care Med. 1996;24:1334-8.

10. Reents W, Muellges W, Franke D, Babin-Ebell J, Elert O. Cerebral oxygen saturation assessed by near-infrared spectroscopy during cor- onary artery bypass grafting and early postoperative cognitive function. Ann Thorac Surg. 2002;74:109-14.

11. Wahr JA, Tremper KK, Samra S, Delpy DT. Near-infrared spectroscopy: theory and applications. J Cardiothorac Vasc Anesth. 1996;10: 406-18.

12. Tanaka H, Kazui T, Sato H, Inoue N, Yamada O, Komatsu S. Experimental study on the optimum flow rate and pressure for selective cerebral perfusion. Ann Thorac Surg. 1995;59:651-7.

13. Testolin L, Roques X, Laborde MN, Roques F, Mukai S, Baudet E. Moderately hypothermic cardiopulmonary bypass and selective cerebral perfusion in ascending aorta and aortic arch surgery. Preliminary experience in twenty-two patients. Cardiovasc Surg. 1998;6:398-405.

14. Owen-Reece H, Smith M, Elwell CE, Goldstone JC. Near infrared spectroscopy. Br J Anaesth. 1999;82:418-26.

15. Madsen PL, Secher NH. Near-infrared oximetry of the brain. Prog Neurobiol. 1999;58:541-60.

16. Metz CE. Basic principles of ROC analysis. Semin Nucl Med. 1978; 8:283-98.

17. Hanley JA, McNeil BJ. The meaning and use of the area under a receiver operating characteristic (ROC) curve. Radiology. 1982;143: 29-36.

18. Samra SK, Dy EA, Welch K, Dorje P, Zelenock GB, Stanley JC. Evaluation of a cerebral oximeter as a monitor of cerebral ischemia during carotid endarterectomy. Anesthesiology. 2000;93:964-70.

19. Yao FS, Tseng CC, Ho CY, Levin SK, Illner P. Cerebral oxygen desaturation is associated with early postoperative neuropsychological dysfunction in patients undergoing cardiac surgery. $J$ Cardiothorac Vasc Anesth. 2004;18:552-8.

20. Kirkpatrick PJ, Lam J, Al-Rawi P, Smielewski P, Czosnyka M. Defining thresholds for critical ischemia by using near-infrared spectroscopy in the adult brain. J Neurosurg. 1998;89:389-94.

21. Young AE, Germon TJ, Barnett NJ, Manara AR, Nelson RJ. Behaviour of near-infrared light in the adult human head: implications for clinical near-infrared spectroscopy. Br J Anaesth. 2000;84:38-42.

22. Mehagnoul-Schipper DJ, van der Kallen BF, Colier WN, van der Sluijs MC, van Erning LJ, Thijssen HO, et al. Simultaneous measurements of cerebral oxygenation changes during brain activation by near-infrared spectroscopy and functional magnetic resonance imaging in healthy young and elderly subjects. Hum Brain Mapp. 2002;16:14-23.

23. Sakamoto T, Zurakowski D, Duebener LF, Lidov HG, Holmes GL, Hurley RJ, et al. Interaction of temperature with hematocrit level and $\mathrm{pH}$ determines safe duration of hypothermic circulatory arrest. $J$ Thorac Cardiovasc Surg. 2004;128:220-32.

24. Kim MB, Ward DS, Cartwright CR, Kolano J, Chlebowski S, Henson LC. Estimation of jugular venous $\mathrm{O}_{2}$ saturation from cerebral oximetry or arterial $\mathrm{O}_{2}$ saturation during isocapnic hypoxia. J Clin Monit Comput. 2000;16:191-9.

25. Nollert G, Mohnle P, Tassani-Prell P, Reichart B. Determinants of cerebral oxygenation during cardiac surgery. Circulation. 1995;92(9 suppl): III27-33.

\section{Discussion}

Dr G. Michael Deeb (Ann Arbor, Mich). I would like to commend the authors for this interesting and thought-provoking presentation. There are 3 areas that I would like to address for discussion.

The first area for discussion is your definition of stroke. Since the ability of a tool to measure the outcome will be dependent on a clear definition, I would like the definition of stroke used in this study. Was it a clinical diagnosis, or was the diagnosis made on the results of an imaging study? Did you have a good thorough neurologic preoperative clinical examination and/or imaging study to use for postoperative comparison?

Dr Olsson. Many of these patients underwent emergency surgery for dissection, and time did not allow preoperative studies regarding cerebral imaging. So the answer to that ques- 
tion is no. And regarding the definition of stroke, it was mainly a clinical one.

Dr Deeb. Did you have any patients who were intubated and asleep preoperatively so you couldn't perform a neurologic evaluation? If you did, how did you determine whether the stroke had happened preoperatively or perioperatively?

Dr Olsson. We did not have any preoperatively intubated patients, and as far as we could judge, we didn't deem any of them to have a clinically obvious stroke preoperatively.

Dr Deeb. The second area that I wanted to address was your sample sizes. I was forced to consider sample size as I was looking at your preoperative comparison of patient characteristics between stroke and nonstroke patients, where you stated there was no significant statistical difference between the 2 groups. Yet looking at the data, I thought there was definite clinical significance.

For instance, the difference between the number of patients with a dissection in the 2 groups was $33 \%$. The difference in the number of patients with a rupture was about $38 \%$. So there were some large numbers that were glaring that didn't have statistical significance but seemed to have clinical significance, and I was wondering if there was a tendency toward a type II statistical error secondary to sample size.

The other reason I questioned the sample size was that if you look at your indices that you used to calculate the areas under the curve for your ROC curves, you used sensitivity and specificity and stated that sensitivity was your most accurate tool, yet the confidence intervals for your sensitivity were very wide, as well as the confidence intervals for your odds ratios. Could you address this issue?

Dr Olsson. Dr Deeb, I think you already have. Of course, the sample sizes are small in this study, and we have to understand that certain conclusions cannot be drawn statistically. But all these indices are intertwined, and they all point in the same direction, lending some support to the idea that what we see is probably close to the truth, even if the statistical evidence for it could be questioned.

Dr Deeb. My last area for discussion is something that was very intriguing to me. When I looked at the patients who had stroke versus those who did not, the glaring difference was suboptimal perfusion. You showed in your tables that none of your patients with stroke had optimal perfusion. You defined optimal flow versus suboptimal flow based on the incidence of bilateral perfusion, whether there was uninterrupted perfusion, as well as the amount of time perfused in relationship to the incidence of stroke. On your review, none of your stroke patients had optimal perfusion. All of the patients who had optimal perfusion did not stroke, which was interesting, and your mean circulatory arrest time was less than 40 minutes.

There are series in the literature which show patients having hypothermic circulatory arrest with no perfusion at all with mean circulatory arrest times less than 40 minutes that have stroke rates $8 \%$ or less. If you put infrared spectroscopy on these patients, they have a distinct drop in their saturation, which is continual and progressive. Yet in your series with antegrade cerebral perfusion, your stroke rate was $13 \%$. Therefore, in hypothermic circulatory arrest less than 40 minutes, is suboptimal perfusion worse than no perfusion? Also, in the instances of no perfusion with infrared spectroscopy which shows a continual dramatic drop, why do these patients, over $90 \%$ of them, not have stroke? What is the sensitivity of infrared spectroscopy in this incidence, and how can you correlate it to the published results?

Dr Olsson. I am not completely sure that I know what you are getting at. First of all, I would like to say what is not shown among these figures is the fact that in an instance perhaps where you start the cerebral perfusion and immediately detect a drop on one side, we have adjusted, for example, the cannula placement to look for kinking and so on and handled that problem immediately, and these instances will not show on the figures, of course. I don't know if that is what you are getting at when you are talking about suboptimal perfusion in stroke patients.

Dr Deeb. What I was getting at was the use of suboptimal cerebral perfusion during hypothermic circulatory arrest. You were so kind as to give me the manuscript, and you had the definitions for suboptimal and optimal perfusion. On the basis of your data with hypothermic circulatory arrest with a mean time less than 40 minutes using antegrade cerebral perfusion with a $13 \%$ stroke rate and comparing these data with previous data published showing hypothermic circulatory arrest with a mean time less than 40 minutes and no cerebral perfusion with a stroke rate of $8 \%$, maybe suboptimal perfusion is more dangerous than no cerebral perfusion for hypothermic circulatory arrest less than 40 minutes.

Dr Olsson. That is an intriguing idea, and without having any evidence for it, many would certainly advocate the opinion that if you have an anticipated circulatory arrest shorter than the time it would take to establish the cerebral perfusion, you should go for circulatory arrest alone.

Dr Joseph Bavaria (Philadelphia, Pa). I enjoyed your talk. We, like you, are using NIRS for most of our cases. For some case, we have noticed immediate changes in the NIRS, and they have really helped us avoid a catastrophe, especially with direct cannulation of the arch vessels like the Kazui technique. However, what I wanted to address with you is the idea of relativity between the left and right or the bilaterality of these numbers. Your conclusion slide said that between a $14 \%$ and $24 \%$ reduction in the NIRS from baseline was a sign of concern. If you had both sides with, say, a $14 \%$ reduction, would you be worried, or is it just really a unilateral issue that you are most worried about?

Dr Olsson. I would be equally worried in both instances, I think. If such a decrease in NIRS readings of that magnitude occurred unilaterally or bilaterally, I would be concerned.

Dr Teruhisa Kazui (Hamamatsu, Japan). Why did the $\mathrm{rSO}_{2}$ fall after the institution of the CPB and before the beginning of the $\mathrm{SACP}$ in the patients with stroke? Does it reflect the malperfusion due to the dissection or retrograde embolization from the distal aorta after the disappearance of the cardiac pulsation?

Dr Olsson. That is something we cannot be sure of as we have believed during the course of the operations we have not had any instance of, for example, cannulation-related malperfusion. However, we do not know what damage the dissection itself has already made, and it could be a possible explanation for several or all of these strokes. 


\section{Appendix E1: Definitions of Diagnostic Indices}

Sensitivity, the ability of a test to accurately identify disease: True positive/True positive + false negative.

Specificity, the ability of a test to accurately exclude disease: True negative/True negative + false positive.

Positive predictive value, proportion of patients with a positive test who have the disease: True positive/ True positive + false positive Assesses the reliability of a positive test.

Negative predictive value, proportion of patients with a negative test who do not have the disease: True negative/True negative + false negative. Assesses the reliability of a negative test.

Positive likelihood ratio $\left(\mathrm{LR}^{+}\right)$, the odds of a positive test result in a patient with the disease by the odds of a positive test in a patient without the disease: Sensitivity $/(1-$ specificity $)$. If $\mathrm{LR}^{+}$increases, the ability to diagnose the disease increases.

Negative likelihood ratio $\left(\mathrm{LR}^{-}\right)$, the odds of a negative test result in patient with the disease by the odds of a negative test in a patient without the disease: $\left(1-\right.$ sensitivity)/specificity. If $\mathrm{LR}^{-}$ decreases, the ability to exclude the disease increases. 
TABLE E1. Arterial blood gas measurements and mean arterial blood pressure before CPB, on CPB, after SACP, at end of CPB, and after CPB in patients without versus with stroke

\begin{tabular}{|c|c|c|c|c|c|}
\hline \multirow[b]{2}{*}{ Variable } & \multirow[b]{2}{*}{ No stroke $(n=40)$} & \multirow[b]{2}{*}{ Stroke $(n=6)$} & \multirow[b]{2}{*}{$P$ value } & \multicolumn{2}{|c|}{ Correlation $(r)^{*}$} \\
\hline & & & & $\mathrm{rSO}_{2}$ right & $\mathrm{rSO}_{2}$ left \\
\hline \multicolumn{6}{|l|}{ Before CPB } \\
\hline $\mathrm{pH}$ & $7.39(0.05)$ & $7.37(0.07)$ & .58 & -0.03 & -0.18 \\
\hline $\mathrm{PaO}_{2}(\mathrm{~mm} \mathrm{Hg})$ & $84.8(65.3)$ & $96.0(57.0)$ & .21 & -0.005 & 0.04 \\
\hline $\mathrm{PaCO}_{2}(\mathrm{~mm} \mathrm{Hg})$ & $39.7(8.6)$ & $38.4(8.0)$ & .63 & 0.17 & 0.26 \\
\hline $\mathrm{SaO}_{2}(\%)$ & $97(5)$ & $98(4)$ & .24 & 0.00 & 0.06 \\
\hline Hematocrit (\%) & $38(9)$ & $36(4)$ & .30 & 0.30 & 0.20 \\
\hline MAP (mm Hg) & $84(22)$ & $63(25)$ & .08 & -0.20 & -0.23 \\
\hline \multicolumn{6}{|l|}{ On CPB } \\
\hline $\mathrm{pH}$ & $7.38(0.08)$ & $7.34(0.19)$ & .79 & -0.23 & -0.20 \\
\hline $\mathrm{PaO}_{2}(\mathrm{~mm} \mathrm{Hg})$ & $206.3(76.5)$ & $180.0(129.0)$ & .83 & -0.23 & -0.16 \\
\hline $\mathrm{PaCO}_{2}(\mathrm{~mm} \mathrm{Hg})$ & $39.7(10.9)$ & $37.9(11.7)$ & .28 & $0.37 \dagger$ & $0.33 \dagger$ \\
\hline $\mathrm{SaO}_{2}(\%)$ & $100(0)$ & $99(1)$ & .16 & $-0.34 \dagger$ & -0.24 \\
\hline Hematocrit (\%) & $26(6)$ & $24(6)$ & .33 & 0.27 & 0.28 \\
\hline MAP (mm Hg) & $55(10)$ & $50(15)$ & .83 & -0.14 & -0.17 \\
\hline \multicolumn{6}{|l|}{ After SACP } \\
\hline $\mathrm{pH}$ & $7.29(0.15)$ & $7.23(0.18)$ & .37 & -0.06 & 0.02 \\
\hline $\mathrm{PaO}_{2}(\mathrm{~mm} \mathrm{Hg})$ & $208.5(90.0)$ & $232.5(63.0)$ & .40 & $-0.39 t$ & $-0.44 \dagger$ \\
\hline $\mathrm{PaCO}_{2}(\mathrm{~mm} \mathrm{Hg})$ & $41.1(13.6)$ & $45.7(10.1)$ & .13 & 0.16 & -0.01 \\
\hline $\mathrm{SaO}_{2}(\%)$ & $100(1)$ & $99(1)$ & .53 & 0.00 & 0.00 \\
\hline Hematocrit (\%) & $26(6)$ & $24(6)$ & .75 & 0.29 & $0.37 \dagger$ \\
\hline MAP (mm Hg) & $50(20)$ & $50(15)$ & .59 & 0.27 & $0.33 \dagger$ \\
\hline \multicolumn{6}{|l|}{ End of CPB } \\
\hline $\mathrm{pH}$ & $7.38(0.07)$ & $7.37(0.11)$ & .60 & -0.06 & 0.13 \\
\hline $\mathrm{PaO}_{2}(\mathrm{~mm} \mathrm{Hg})$ & $177.0(86.3)$ & $243.0(202.5)$ & .15 & -0.11 & -0.20 \\
\hline $\mathrm{PaCO}_{2}(\mathrm{~mm} \mathrm{Hg})$ & $35.2(3.7)$ & $36.4(6.3)$ & .96 & -0.02 & -0.24 \\
\hline $\mathrm{SaO}_{2}(\%)$ & $100(0.5)$ & $100(1)$ & .78 & -0.14 & -0.28 \\
\hline Hematocrit (\%) & $27(4)$ & $27(5)$ & .73 & 0.06 & -0.06 \\
\hline $\mathrm{MAP}(\mathrm{mm} \mathrm{Hg})$ & $60(9)$ & $55(10)$ & .24 & -0.03 & 0.00 \\
\hline \multicolumn{6}{|l|}{ After CPB } \\
\hline $\mathrm{pH}$ & $7.39(0.08)$ & $7.39(0.05)$ & .26 & -0.18 & -0.30 \\
\hline $\mathrm{PaO}_{2}(\mathrm{~mm} \mathrm{Hg})$ & 111.8 (92.2) & $144.8(62.3)$ & .21 & 0.35 & 0.20 \\
\hline $\mathrm{PaCO}_{2}(\mathrm{~mm} \mathrm{Hg})$ & $36.8(7.0)$ & 38.7 (3.7) & .26 & 0.18 & 0.11 \\
\hline $\mathrm{SaO}_{2}(\%)$ & $99(3.5)$ & $99(1)$ & .36 & 0.35 & 0.14 \\
\hline Hematocrit (\%) & $30(7)$ & $30(8)$ & .78 & 0.24 & 0.11 \\
\hline $\mathrm{MAP}(\mathrm{mm} \mathrm{Hg})$ & $64(10)$ & $63(14)$ & .94 & 0.05 & 0.16 \\
\hline
\end{tabular}

Data are median (interquartile range). $C P B$, Cardiopulmonary bypass; $S A C P$, selective antegrade cerebral perfusion; $P a 0_{2}$, arterial partial tension of oxygen; $\mathrm{PaCO}_{2}$, arterial partial tension of carbon dioxide; $\mathrm{SaO}_{2}$, arterial oxygen saturation; $M A P$, mean arterial pressure; $\mathrm{rSO}_{2}$, regional cerebral tissue oxygen saturation. *Correlation between $\mathrm{rSO}_{2}$ and variable in patients without stroke. $† P<.05$. 